\title{
Morte encefálica: diagnóstico possível sem utilização de exames complementares
}

\author{
Fernanda de Paula Pimenta1, Bárbara Rios Vellasco Amorim¹, Ledismar José Silva² \\ Hospital de Urgências de Goiânia Dr. Valdemiro Cruz (HUGO) e Hospital Santa Mônica, Goiânia, Goiás.
}

\section{RESUMO}

Objetivo: A necessidade da utilização de testes confirmatórios para o diagnóstico de morte encefálica vem sendo questionada nos últimos tempos. Acredita-se que o exame clínico completo, realizado de acordo com o protocolo do Conselho Federal de Medicina, seja suficiente para constatar a ausência irreversível de função no tronco encefálico. Assim, este estudo teve como objetivo averiguar a real necessidade da utilização de exames complementares no diagnóstico de morte encefálica. Método: Foi realizado estudo prospectivo analisando os prontuários de pacientes que receberam diagnóstico de morte encefálica desde a abertura do protocolo até a realização dos exames clínicos completos e exame complementar (Doppler transcraniano). Resultados: Não foi registrado nenhum caso de recuperação da função cortical elou do tronco cerebral após o diagnóstico de morte encefálica utilizando os critérios clínicos. A dificuldade para a realização do Doppler transcraniano e as falhas inerentes ao exame contribuíram para tornar mais lento o diagnóstico. Conclusão: É possível diagnosticar morte encefálica apenas utilizando exame clínico completo, sem a necessidade de exames complementares.

\section{PALAVRAS-CHAVE}

Morte encefálica, diagnóstico clínico, estudos prospectivos.

\begin{abstract}
Brain death: possible diagnosis without complementary exams

Objective: The need to use confirmatory tests for brain death diagnosis has been questioned lately. It is believed that a full clinical examination, performed according to the protocol of brain death diagnosis of the Brazilian National Council of Medicine, is sufficient to certify the irreversible loss of brain-stem function. Therefore, this study aimed to verify the real need to use complementary exams for brain death diagnosis. Method: We carried out a prospective study analyzing the files of patients with brain death diagnoses since the beginning of the protocol and that underwent a full clinical examination and transcranial Doppler as a complementary exam. Results: No cases of cortical and/or brain-stem function recovery after brain death diagnosis using clinical criteria were registered. Difficulty to perform transcranial Doppler and failures inherent to the exam contributed to late diagnosis. Conclusion: It is possible to diagnose brain death only using a full clinical examination, with no need to perform complementary exams.
\end{abstract}

\section{KEYWORDS}

Brain death, clinical diagnosis, prospective studies.

\section{Introdução}

O conceito de morte vem sofrendo mudanças no decorrer do tempo. Os avanços da medicina, que incluem técnicas de ressuscitação cardíaca, respiradores artificiais e circulação extracorpórea, tornaram obsoleta a definição tradicional de morte clínica, que incluía apenas a cessação irreversível das funções cardíaca e respiratória. ${ }^{1} \mathrm{O}$ novo conceito de morte, formulado em 1981 pela President's Commission for the Study of Ethical Problems in Medicine and Biomedical and Behavioral Research, dos Estados Unidos, amplamente aceito até hoje, define-a como a cessação irreversível das funções cardíacas, respiratórias e de todo o encéfalo, em especial o tronco encefálico. ${ }^{1,2}$

Os critérios para diagnóstico de morte encefálica (ME) no Brasil são baseados na constatação clínica

1. Acadêmica de Medicina da Pontifícia Universidade Católica de Goiás (PUC-GO), Goiânia, GO, Brasil.

2. Neurocirurgião e docente do Departamento de Medicina da PUC-GO, Goiânia, GO, Brasil. 
de coma aperceptivo e ausência de reflexos ou movimentos supraespinais, sendo excluídas as situações de causas reversíveis de coma, como hipotermia, uso de medicamentos depressores do sistema nervoso central, distúrbio metabólico e hidroeletrolítico. Tal achado clínico deve, necessariamente, ser respaldado por um exame complementar que demonstre inequivocamente ausência de atividade elétrica, de perfusão sanguínea cerebral ou de atividade metabólica encefálica. ${ }^{2,3}$

Em 1995, a American Neurological Association (ANA) organizou um comitê que definiu os critérios atualmente utilizados nos Estados Unidos e copiado em vários outros países. ${ }^{4}$ Nunca foi relatado ou demonstrado um único caso de recuperação da função cortical e/ou do tronco cerebral após o diagnóstico de ME utilizando os critérios da ANA estabelecidos em 1995. ${ }^{5}$

O protocolo de diagnóstico de ME no Brasil, aprovado pelo Conselho Federal de Medicina (CFM), segue quase completamente as diretrizes firmadas pela ANA em 1995, exceto pelo fato da não obrigatoriedade da realização do exame complementar. ${ }^{5,6}$

A necessidade da utilização de testes confirmatórios para o diagnóstico de $\mathrm{ME}$ vem sendo questionada incessantemente nos últimos anos. ${ }^{7}$ Em inúmeros artigos científicos, os autores afirmam que o exame neurológico é suficiente para o diagnóstico preciso de ME sem a necessidade de exames complementares. ${ }^{2.4,6-10}$ Para isso, de acordo com nossas observações, é necessário que o exame clínico seja realizado por médicos habilitados.

Em alguns países, como Franca, Argentina, México e Holanda, os testes confirmatórios são obrigatórios, enquanto em outros, como Alemanha, Portugal, Rússia e Dinamarca, são opcionais. ${ }^{4}$ Nos Estados Unidos, a determinação de ME é baseada em avaliação clínica completa, incluindo pesquisa de reflexos do tronco encefálico e teste da apneia. O exame confirmatório em adultos não é obrigatório, sendo realizado apenas quando o exame clínico foi incompleto ou inconclusivo. ${ }^{8,9}$

De acordo com o protocolo da ANA, o exame complementar apenas é indicado quando há trauma facial severo, anormalidade pupilar preexistente, níveis tóxicos de quaisquer drogas sedativas, uso de aminoglicosídeos, antidepressivos tricíclicos e anticolinérgicos, apneia do sono ou doença pulmonar obstrutiva severa com retenção de $\mathrm{CO}_{2}$.

O Doppler transcraniano (DTC) é o exame complementar utilizado nos hospitais em que esta pesquisa foi realizada. É um exame operador-dependente e em $10 \%$ dos pacientes não é possível insonação das artérias intracranianas. ${ }^{11}$

Um resultado falso-negativo (DTC indica fluxo sanguíneo cerebral, mas clinicamente o paciente preenche os critérios de $\mathrm{ME}$ ) resulta na necessidade de repetição do exame complementar. $\mathrm{Na}$ realidade brasileira, a realização de exames sequenciais não é rápida, o que retarda o diagnóstico definitivo. A demora no diagnóstico pode inviabilizar uma possível doação de órgãos, pois o paciente fica mais suscetível a disfunções orgânicas e instabilidade hemodinâmica, podendo evoluir para parada cardiorrespiratória (PCR).

$\mathrm{O}$ espetacular progresso médico-científico na área de transplantes nas últimas décadas propicia interesse crescente da sociedade quanto ao conceito e aos critérios diagnósticos de ME, pela óbvia razão de que nesse grupo de pacientes encontram-se potenciais doadores de múltiplos órgãos. ${ }^{12}$

$\mathrm{O}$ conceito de $\mathrm{ME}$ não é fundamental apenas para o transplante de órgãos, porquanto também é uma forma de não prolongar o sofrimento e a angústia dos familiares do paciente, independentemente de serem favoráveis ou não à doação de órgãos. ${ }^{8}$

Pela experiência do autor deste projeto em trabalhos com a equipe de transplantes e captação de órgãos de Goiânia, quando era o médico responsável pela realização dos exames complementares, em particular o DTC, foram observados pacientes com DTC evidenciando fluxo sanguíneo cerebral não convergindo com o exame clínico de ME. Todos os pacientes confirmados clinicamente com ME evoluíram para PCR, inviabilizando a captação de seus órgãos, de acordo com as normas do CFM em vigência, embora muitos deles fossem doadores de órgãos declarados.

No Brasil, 63.975 pacientes aguardavam transplantes de órgãos em 2006. ${ }^{13}$ Por conta das falhas inerentes dos exames complementares, em associação à dificuldade técnica de realizá-los, surgem dúvidas sobre a real necessidade de sua execução. ${ }^{8}$

A doação de órgãos bem-sucedida depende da relação de confiança estabelecida entre as equipes médica e da central de captação de órgãos e a família do potencial doador, bem como da agilidade do processo de confirmação da ME. Maior rapidez no diagnóstico de ME apenas com a utilização do exame clínico completo poderia aumentar o número de órgãos captados em tempo hábil. A demora em estabelecer o diagnóstico de ME exerce impacto significativo sobre o bem-estar, as probabilidades de cura e a extensão de sequelas nos pacientes que aguardam pela doação de órgãos, bem como sobre seus familiares e a sociedade. ${ }^{14}$

Assim sendo, este estudo teve como objetivo averiguar a real necessidade da utilização de exames complementares no diagnóstico de ME, comparando seus resultados com os de exames clínicos, com o intuito de averiguar a possibilidade de diagnóstico apenas pelo exame clínico, visando diminuir o tempo gasto entre a confirmação da ME e a captação de órgãos. 


\section{Materiais e métodos}

O presente estudo foi realizado de forma prospectiva, coletando dados de prontuários e resultados do DTC de 21 pacientes, maiores de 18 anos, que preenchiam os critérios do protocolo de diagnóstico de ME do CFM, internados no Hospital de Urgências de Goiânia Dr. Valdemiro Cruz (HUGO) e no Hospital Santa Mônica, ambos no município de Goiânia/GO, no período de março a outubro de 2011.

Para a análise dos dados, foi utilizado o método qui-quadrado $\left(\chi^{2}\right)$. As variáveis avaliadas foram: o tempo decorrido entre a abertura do protocolo de diagnóstico de ME e o óbito do paciente; o tempo decorrido entre o primeiro e o segundo exames clínicos; o tempo decorrido entre a confirmação clínica da $\mathrm{ME}$ e a realização do DTC; o número de pacientes declaradamente doadores; e o número total de doações realizadas.

\section{Resultados}

Foram analisados os prontuários de 21 pacientes com provável ME e 100\% dos exames clínicos confirmaram o diagnóstico. Em apenas 13\% dos pacientes avaliados, o segundo exame clínico foi realizado até 6 horas após o primeiro exame, como recomendado no protocolo de diagnóstico de ME do CFM. Em decorrência de complicações, provavelmente justificadas pela demora em obter o diagnóstico final, 14\% dos pacientes morreram antes do segundo exame clínico.

Em $43 \%$ dos pacientes avaliados, foi realizado o exame complementar. Em nenhum paciente, o DTC foi realizado imediatamente após o segundo exame clínico; em $24 \%$ deles, o DTC foi realizado após 12 horas e em $28 \%$, após 24 horas da confirmação clínica da ME; $16 \%$ dos pacientes morreram aguardando a realização do exame complementar. Vale ressaltar que, entre os pacientes avaliados, oito eram doadores de órgãos (38\%), mas em apenas dois casos houve a efetiva captação de órgãos (25\%).

Em 33\% dos pacientes que realizaram DTC não foi confirmada ME, divergindo do diagnóstico clínico completo. Todos os pacientes com diagnóstico clínico de ME, mesmo com o DTC demonstrando fluxo sanguíneo cerebral, evoluíram para parada cardíaca em menos de cinco dias.

O tempo entre a abertura do protocolo e a parada cardíaca do paciente variou entre 12 horas e 120 horas, com a grande maioria evoluindo para PCR em menos de 72 horas, como pode ser verificado na Figura 1.

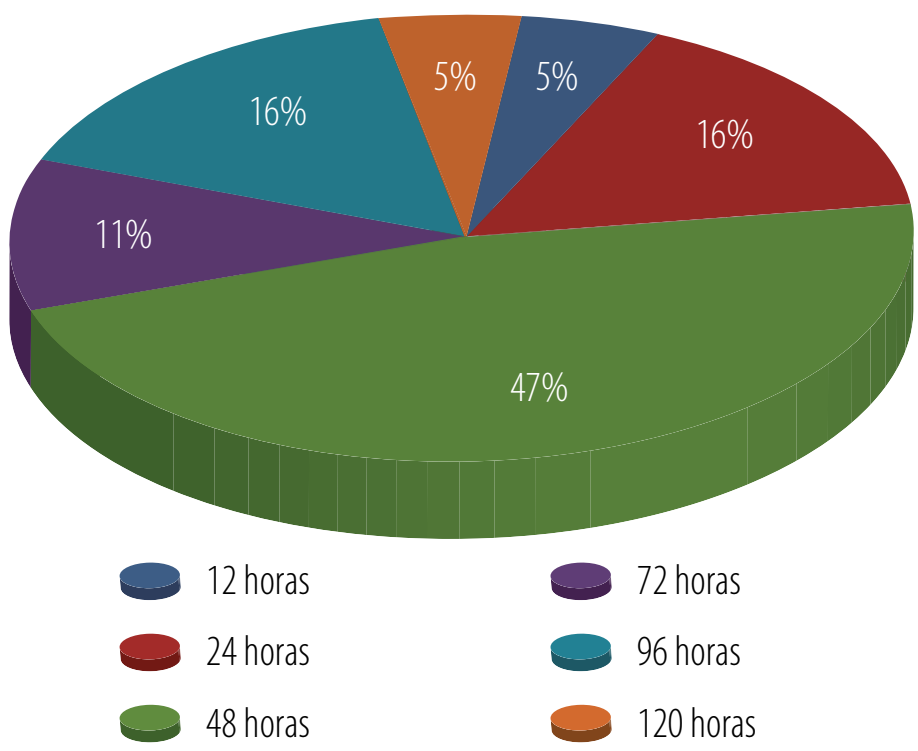

Figura 1 - Tempo decorrido entre a abertura do protocolo e o óbito. 


\section{Discussão}

O protocolo de diagnóstico de ME no Brasil estabelece que, em pacientes acima de 2 anos de idade, deve haver um intervalo de 6 horas entre os dois exames clínicos. ${ }^{4}$

Observamos que, em $87 \%$ dos pacientes, o segundo exame ocorreu 6 horas após o primeiro. $\mathrm{O}$ aumento do intervalo de tempo entre o primeiro e o segundo exames clínicos afeta diretamente as doações de órgãos, pois $14 \%$ dos pacientes estudados tiveram parada cardíaca enquanto aguardavam a realização do segundo exame clínico e seus órgãos não puderam ser doados.

Potenciais doadores não sobrevivem mais do que 72 horas e os órgãos transplantáveis resistem poucos dias ou mesmo poucas horas: coração e pulmões duram de 4 a 6 horas, pâncreas, de 12 a 24 horas, fígado, de 12 a 24 horas e rins, até 48 horas. ${ }^{14}$

Assim sendo, o exame complementar deve ser realizado prontamente ao término do segundo exame clínico. Contudo, observamos longa demora também para a realização do DTC, principalmente porque são poucos os médicos habilitados para executá-lo.

De acordo com os dados que coletamos, em apenas $52 \%$ dos pacientes foi realizado o exame complementar, e em $13 \%$ deles o DTC não foi realizado pelo fato de o paciente não ser doador ou apresentar contraindicação clínica, como sepse. Além disso, todos os DTCs realizados só ocorreram 12 horas após o exame clínico final, o que, provavelmente, explica o fato de que $16 \%$ dos pacientes tiveram parada cardíaca entre a realização do segundo exame clínico e a do exame complementar, trazendo como consequência a perda de captação de seus órgãos para transplante.

Além da demora na realização do DTC, em 33\% dos pacientes, o exame demonstrou fluxo sanguíneo cerebral, não confirmando a ME diagnosticada clinicamente. Embora o DTC não tenha sido confirmatório para ME, $100 \%$ dos pacientes com diagnóstico clínico de ME evoluíram com parada cardíaca em menos de cinco dias.

Em outro estudo, todos os pacientes com diagnóstico clínico de ME e DTC demonstrando óbvio fluxo sanguíneo cerebral evoluíram para colapso circulatório encefálico total, observando-se que a demora no diagnóstico por exame complementar contribuiu para a perda de possíveis doadores. ${ }^{5}$

Dos 21 pacientes avaliados em nosso estudo, 13 eram doadores declarados (62\%) e, desses, apenas três, ou seja, $23 \%$ deles, tiveram seus órgãos efetivamente doados para transplante, beneficiando outros pacientes. A demora, inicialmente para o diagnóstico clínico de ME e, posteriormente, para o diagnóstico pelo exame complementar, contribuiu para a perda da captação de órgãos de pacientes potencialmente doadores, pois estes evoluíram para PCR.

Os dados analisados no presente estudo demonstram que a utilização de exames complementares como método diagnóstico de ME é discutível. Todos os pacientes avaliados que tiveram diagnóstico clínico de ME evoluíram para PCR com ou sem confirmação pelo exame complementar. Isso evidencia a segurança e a eficácia do diagnóstico clínico feito adequadamente.

\section{Conclusão}

O exame clínico realizado por médicos capacitados é suficiente para o diagnóstico de ME sem a necessidade de exames complementares. Nos hospitais estudados, observou-se demora substancial para a realização de exames clínicos e complementares, o que contribui sobremaneira para a perda de prováveis doadores de órgãos. Embora tenha ocorrido divergência entre os achados clínicos e sonográficos, todos os pacientes com fluxo sanguíneo cerebral confirmado por DTC e que apresentaram confirmação pelo exame clínico evoluíram, invariavelmente, para colapso circulatório encefálico total.

\section{Referências}

1. Stevens RD, Bhardwaj A. Approach to the comatose patient. Crit Care Med. 2006;34(1):31-41.

2. Terra CM, Bousso A, Martins FRP, Silva AFA, Fernandes JC, Baldacci ER, et al. Morte encefálica: análise. Pediatria. 1994;16(3):102-12. Disponível em: http://www. pediatriasaopaulo.usp.br/upload/pdf/163.pdf. Acesso em: 7/10/2010.

3. Conselho Federal de Medicina. Resolução CFM $n^{\circ}$ 1.480/97. Disponível em: http://www.portalmedico.org. $\mathrm{br} /$ resolucoes/cfm/1997/1480_1997.htm. Acesso em: 9/10/2010.

4. Wijdicks EF. Brain death worldwide: accepted fact but no global consensus in diagnostic criteria. Neurology. 2002;58(1):20-5.

5. Dosemeci L, Dora B, Yilmaz M, Cengiz M, Balkan S, Ramazanoglu A. Utility of transcranial Doppler ultrasonography for confirmatory diagnosis of brain death: two sides of the coin. Transplantation. 2004;77(1):71-5.

6. Morato EG. Morte encefálica: conceitos essenciais, diagnóstico e atualização. Rev Med Minas Gerais. 2009;19(3):227-36. Disponível em: http://www.medicina. ufmg.br/rmmg/index.php/rmmg/article/viewFile/164/147. Acesso em: 7/10/2010.

7. Wijdicks EF, Varelas PN, Gronseth GS, Greer DM. Evidencebased guideline update: determining brain death in adults: report of the Quality Standards Subcommittee of the American Academy of Neurology. Neurology. 
2010;74(23):1911-8. Disponível em: http://www.aaprott. org.ar/Update\%20Brain\%20Death\%202010.pdf. Acesso em: 11/10/2010.

8. Wijdicks EF. The case against confirmatory tests for determining brain death in adults. Neurology. 2010;75(1):77-83.

9. Practice parameters for determining brain death in adults (summary statement). The Quality Standards Subcommittee of the American Academy of Neurology. Neurology. 1995;45(5):1012-4. Disponível em: http://www.neurology. org/content/45/5/1012.full.pdf. Acesso em: 11/10/2010.

10. Wijdicks EF. Determining brain death in adults. Neurology. 1995;45(5):1003-11.

11. Aaslid R, Markwalder TM, Nornes H. Noninvasive transcranial Doppler ultrasound recording of flow velocity in basal cerebral arteries. J Neurosurg. 1982;57(6):769-74.

12. Barclay WR. Guidelines for the determination of death. JAMA. 1981;246(19):2194.
13. Marinho A, Cardoso SS, Almeida VV. Os transplantes de órgãos nos estados brasileiros. Rio de Janeiro: Instituto de Pesquisa Econômica Aplicada; 2007. Disponível em: http:// www.ipea.gov.br/sites/000/2/publicacoes/tds/td_1317.pdf. Acesso em: 10/10/2010.

14. Marinho A. [A study on organ transplantation waiting lines in Brazil's Unified National Health System]. Cad Saude Publica. 2006;22(10):2229-39.

\section{Comentários}

Embora seja a única certeza que temos em vida, a morte é um motivo de preocupação entre nós. Por isso, quando lidamos com esse assunto, devemos entendê-lo como algo abstrato e sempre polêmico.

É evidente que a ciência mostra-nos diretrizes a serem seguidas, mas não podemos deixar de considerar o sentimento das pessoas envolvidas.

Como bem afirmam os autores, o processo pelo qual uma pessoa falece tem, atualmente, seu ponto de irreversibilidade na ausência de atividade encefálica e não mais, como no passado, na ausência de atividade cardiorrespiratória. Esse conceito introduzido pelos estudiosos do tema é hoje aceito pela grande maioria da população leiga. Foi precisamente esse conceito que deu impulso aos transplantes, uma vez que permitiu a retirada dos órgãos em estado de viabilidade.

Entretanto, ainda há certa desconfiança sobre a realidade da morte, sobretudo quando familiares não têm uma estreita relação com a equipe médica.

Por isso, no sentido de resguardar possíveis problemas jurídicos a posteriori, é que o Conselho Federal de Medicina (CFM), em sua Resolução n 1.480/97, orienta para a realização de exame paraclínico, que servirá como documento.

Não tenho dúvida de que os médicos em geral, neurologistas e intensivistas em particular, sabem perfeitamente diagnosticar a morte encefálica sem ter de recorrer a exames complementares, exceto em casos especiais como já foi referido neste trabalho.

Os autores introduzem a matéria de forma adequada, já apontando para uma tendência geral quanto à não realização de complementação ao exame clínico.

Os resultados, assim como a metodologia utilizada, são apresentados de forma a esclarecer bem a estrutura da pesquisa.

A discussão e a conclusão mostram claramente que, muitas vezes, a complementação dos dois exames clínicos, além de desnecessária, acaba por impedir que um transplante seja realizado.

O número de casos apresentados neste artigo é insuficiente para que o CFM tenda a alterar a resolução. Seria preciso que mais médicos tivessem a iniciativa de publicar artigos sobre o tema. Um número significativo de trabalhos, seguidos de campanha de esclarecimento, poderia modificar a declaração de morte encefálica, eliminando a complementação ao exame clínico.

Dr. Roberto Godoy São Paulo - SP 
O artigo apresentado tem boa apresentação formal e obedece sobre esse aspecto às condições para publicação. As conclusões e a proposição delas decorrentes merecem alguns comentários dada a relevância ética do diagnóstico de morte encefálica.

O Conselho Federal de Medicina, por delegação que lhe confere a lei, editou a Resolução no 1.480 que disciplina o assunto, estabelecendo as condições e os limites para o diagnóstico de morte encefálica, baseando-se os legisladores nos aspectos fisiopatológicos, éticos e psicossociais que envolvem tal conclusão.

A Resolução no 1.480 leva em conta nos seus "consideranda" os critérios já estabelecidos para o diagnóstico pela comunidade científica mundial como também a necessidade de indicação judiciosa da suspensão das medidas de suporte à vida e da adoção de critério indiscutível de constatação da ocorrência da morte. Nesta última condição, enquadra-se a realização do exame complementar.

Os autores se baseiam no fato de que, em outros países, o exame complementar não é exigido e acrescento, àqueles citados no artigo, a Alemanha. Argumentam ainda que não há registro de erros no diagnóstico de morte encefálica em séries publicadas as quais acrescentam a própria, o que dispensaria a realização de exames complementares. Não levam em conta a falta de evidência confiável dos dados apresentados.

Não há na argumentação nenhuma referência à possibilidade de resultados falsos-negativos ou positivos nos diagnósticos clínicos de morte encefálica, condição que deve ser admitida como o fazem Iltis e Cherry¹.

O artigo também não leva em conta que a regulamentação dos transplantes tem o objetivo de demonstrar aos doadores em vida e aos familiares, após a morte, a certeza absoluta do diagnóstico de morte encefálica que não pode, de nenhuma maneira, estar sujeito a qualquer subjetividade ou, na pior das hipóteses, à qualificação deficiente dos profissionais envolvidos no diagnóstico.

A doação é um ato voluntário e não prescinde da confiança irrestrita na certeza do diagnóstico de morte encefálica. Os exames complementares que demonstram a cessação da atividade elétrica e da perfusão sanguínea não estão sujeitos à subjetividade e são irrefutáveis, proporcionando, assim, a necessária credibilidade do diagnóstico.

Por fim, todas as medidas de cautela necessárias são adotadas na proteção dos doadores que, em nenhuma hipótese, podem ficar à mercê de equívocos, omissões ou malgré tout aos conflitos de interesses, infelizmente cada vez mais presentes na vida contemporânea.

Dr. Clemente Brito Pereira São Paulo - SP

\section{Referência}

1. Iltis AS, Cherry MJ. Death revisited: rethinking death and the dead donor rule. J Med Philos. 2010;35:223-41. 